\title{
Pengaruh Hipnosis dalam Meningkatkan Kepercayaan Diri Anggota Sriwijaya Hypno-Pranic Association Palembang
}

\author{
Regista Ramadhania $^{a^{*}, \text { Listya Istiningtyas }}{ }^{\text {b }}$, Eko Oktapiya Hadinata ${ }^{\text {c }}$ \\ ${ }^{a, b, c}$ Universitas Islam Negeri Raden Fatah Palembang \\ *Corresponding author: Registanhia@gmail.com
}

\begin{abstract}
Abstrak
Penelitian ini bertujuan untuk mengetahui pengaruh hipnosis dalam meningkatkan kepercayaan diri pada anggota Sriwijaya Hypno-Pranic Association Palembang. Jenis penelitian yang digunakan adalah Eksperimen Murni dengan desain Pretest Posttest Control Group Design. Sampel dalam penelitian ini berjumlah 3 orang anggota Sriwijaya HypnoPranic Association kelompok eksperimen dan 3 orang kelompok kontrol dengan pemilihan subjek menggunakan teknik purposive sampling. Instrumen penelitian yang digunakan adalah skala kepercayaan diri, checklist observasi kepercayaan diri serta kuesioner kepercayaan diri yang dianalisis dengan Independent Sample T-test dengan bantuan program SPSS versi 22 for windows. Hasil penelitian skala kepercayaan diri didapatkan nilai $t$ hitung $(4,596)>\mathrm{t}$ tabel $(2,774)$ dan hasil signifikansi $(4,596)>\mathrm{t}$ tabel $(2,774)$, dan hasil dari kuesioner didapatkan $\mathrm{t}$ hitung $(4,596)>\mathrm{t}$ tabel $(2,776)$ dan hasil signifikansi $(2$-tailed $)(0,10)$ dan $(0,27)<\mathrm{a}(0,05)$. Dari hasil penelitian, dapat disimpulkan bahwa ada pengaruh hipnosis dalam meningkatkan kepercayaan diri pada anggota Sriwijaya Hypno-Pranic Association Palembang.
\end{abstract}

\section{Kata Kunci}

Hipnosis; Kepercayaan diri; Independent Sample T-Test

\begin{abstract}
The purpose of this study is the influence of hypnosis in increasing confidence in members of Sriwijaya Hypno-Pranic Association Palembang. This type of research is a pure experiment with a pretest posttest control group design. The sample in this study consisted of 3 members of the Sriwijaya Hypno-Pranic Association experimental group and 3 control groups with subject selection using purposive sampling technique. The research instrument used was a selfconfidence scale, a self-confidence observation checklist and a self-confidence questionnaire which were analyzed using the Independent Sample T-test with the help of the SPSS program version 22 for windows. The results of the research on the self-confidence scale obtained $t$ value (4.596) $>$ t table (2.774) and significance results (4.596) $>$ t table (2.774), and the results of the questionnaire obtained $t$ count (4.596) $>t$ table (2.776) and the results of significance (2-tailed) (0.10) and (0.27) <a (0.05). From the results of the research, it can be concluded that there is an effect of hypnosis in increasing self-confidence in members of the Palembang Sriwijaya Hypno-Pranic Association.
\end{abstract}

\section{Keywords}

Hypnosis; Self-confident; Independent Sample T-Test 


\section{Pendahuluan}

$\mathrm{M}$

engaktualisasi diri merupakan kebutuhan yang paling tinggi pada manusia dalam teori

Malsow. Menurut Maslow (2018), kepercayaan diri ialah faktor yang begitu penting dalam menggapai keberhasilan yang diinginkan. Kepercayaan diri merupakan asset penting bagi setiap individu. Adanya kepercayaan diri yang baik, individu dapat bebas mengekspresikan berbagai keinginan dan ambisi untuk hal yang lebih luas dalam kehidupannya. Di samping itu, dalam melanjutkan dan mempertahankan hidup manusia perlu bekerja untuk memenuhi kebutuhan. Dan dalam pekerjaan apapun manusia harus memiliki kepercayaan diri yang baik agar tercapai apa yang diinginkan dan terpenuhi segala kebutuhan.

Dalam dunia pekerjaan setiap orang kerap berlomba dalam meningkatkan kemampuan yang dimiliki untuk tetap berguna dan bertahan hidup. Namun tak semudah itu, masih ada beberapa yang merasa belum mampu mengaplikasikan kemampuannya untuk hal positif bagi dirinya dan orang lain. Padahal secara teori sudah memahami bagaimana cara mengaplikasikan apa yang sudah digandrungi. itulah yang disebut sebagai kurangnya kepercayaan diri pada potensi yang dimiliki. Menurut Taylor (2013), percaya diri (self confidence) adalah kepercayaan seorang pada potensi yang dimiliki untuk mengekspresikan tindakan tertentu atau untuk menggapai target yang diinginkan. Dengan kata lain, kepercayaan diri adalah merasakan seperti apa keseluruhan tentang diri kita, dan perilaku merefleksikan bagaimana kita.
Menurut Lauster (Ghufron \& Risnawita, 2012), kepercayaan diri adalah suatu perasaan yakin atas potensi yang dimiliki diri sehingga yang bersangkutan tidak terlalu khawatir dalam mengekspresikan tindakannya, dapat merasa leluasa untuk melakukan hal-hal yang disenanginya dan bertanggung jawab atas apa yang dilakukan, sopan dan hangat dalam berinteraksi dan berkomunikasi dengan orang lain, dapat menghargai orang lain, dapat mengenal kelebihan dan kekurangannya serta memiliki dorongan untuk berprestasi. Adapun lima aspek kepercayaan diri menurut teori Lauster; pertama, yakin pada potensi sendiri yaitu, suatu kepercayaan atas diri sendiri terhadap apapun fenomena yang berhubungan dengan kemampuan individu untuk menghadapi fenomena yang terjadi tersebut. Kedua, optimis yaitu, selalu memiliki sudut pandang yang positif. Ketiga, objektif yaitu, adanya evaluasi yang baik dalam diri, baik pandangan maupun tindakan yang dilakukan memunculkan efek positif terhadap diri sendiri. Keempat, bertanggung jawab yaitu, berani menanggung konsekuensi yang harus dihadapi. Kelima, rasional dan realistis yaitu, menghadapi segala sesuatu dengan menggunakan hasil dari pemikiran yang diterima oleh akal (Ghufron \& Risnawita, 2012). Dalam hipnoterapi, terapis harus mengetahui elemen-elemen yang sangat penting dalam sesi terapi itu sendiri karena ada banyak faktor yang dapat mempengaruhi keberhasilan sesi terapi tersebut, salah satunya terapis harus yakin akan kemampuan dirinya, percaya diri dan terampil (Aprillia, 2010). Rasa percaya diri seorang terapis berguna selama proses terapi. Karena, ketika terapis mengalami ketidakpercayaan diri terhadap kemampuannya, maka hal itu akan 
menyebabkan pemberian pelayanan bimbingan terapi yang kurang baik bahkan dapat menyimpang.

Menurut Gunawan (2012), hipnosis merupakan sugesti yang menggunakan tehnik-tehnik tertentu untuk membantu para klien meningkatkan diri mereka, berdasarkan permasalahan yang mereka alami. Sejalan dengan yang dikemukakan oleh Ormond McGill (Wong \& Hakim, 2009), sebuah proses hipnosis merupakan perpaduan antara dua faktor, yaitu faktor physiological (percaya diri, keyakinan, citra diri) dan faktor psychological (pengetahuan mengenai sugesti). Dengan kata lain, hipnosis merupakan sebuah psikoterapi yang dapat membantu klien dalam menyelesaikan berbagai masalah yang dihadapi dengan pemberian sugesti yang bersifat positif sehingga membantu pola pikir klien menjadi lebih baik dalam memahami tentang dirinya. Dalam dunia psikologi, hipnosis merupakan salah satu cabang ilmu psikologi yang mengkaji tentang manfaat sugesti untuk mengendalikan dan mengatasi masalah kognisi (pikiran), afeksi (perasaan), dan perilaku. Hipnosis juga termasuk suatu metode terapi pikiran dan pengobatan yang menggunakan metode hipnosis untuk memberi sugesti atau perintah positif kepada pikiran bawah sadar pada gangguan psikologis atau untuk mengontrol perasaan, pikiran dan perilaku seseorang untuk menjadi lebih baik (Irianto, dkk., 2014).

Dalam dunia psikoterapi, hipnosis tidak hanya digunakan dalam psikoterapi pendukung, namun lebih dari itu. Hipnosis adalah alternatif yang efektif dalam psikoterapi pendalaman konsentrasi dengan tujuan membangun kembali (rekonstruktif), sehingga perlu pengkajian yang lebih serius agar tercapai suatu pendekatan intim dan menyeluruh. Perlu diketahui bahwa hipnosis telah dikaji oleh berbagai bidang kehidupan untuk meningkatkan sumber daya dan kualitas seseorang untuk menuju titik optimal yang terbaik dalam hidupanya (Hakim, 2010). Dengan kata lain, teknik psikoterapi hipnosis mampu menjadi alternatif stimulus individu untuk meningkatkan kepercayaan di dalam diri seseorang. Berdasarkan uraian diatas, peneliti tertarik untuk melakukan penelitian yang bertujuan untuk mengetahui pengaruh hipnosis dalam meningkatkan kepercayaan diri pada anggota Sriwijaya Hypno-Pranic Association Palembang.

\section{Metode}

Penelitian ini menggunakan penelitian eksperimental. Penelitian eksperimental mempelajari tentang ikatan sebab-akibat tidak hanya antar variabel tetapi hubungan kausal antara variabel bebas dan variabel tergantung (terikat). Penelitian ini termasuk dalam penelitian eksperimen murni. Eksperimen murni ialah jenis penelitian eksperimen yang terkuat. Jenis penelitian eksperimen ini disebut sebagai true experiment karena dalam desain ini peneliti dapat mengendalikan seluruh variabel luar yang mempengaruhi proses eksperimen (Payadnya \& Jayantika, 2018).

\section{Desain Penelitian}

Desain penelitian yang digunakan yakni desain penelitian dua kelompok, yakni Pretest-Posttest Control Group Design. Dimana terdapat dua kelompok yang masing-masing dipilih secara random (R), kemudian diberi pre-test untuk mengenali kondisi awal. Baru kemudian perlakuan 
diberikan pada kelompok eksperimen. Setelah itu, baru post-test diberikan pada kedua kelompok untuk dilihat adakah perbandingan antara kelompok eksperimen dan kelompok kontrol. Hal ini biasanya sering disebut dengan istilah pretestposttest control group design. Adapun perincian lebih detail dapat dilihat dari tabel 1.

Tabel 1.

Detail Penelitian

\begin{tabular}{lccc}
\hline Kelompok & $\begin{array}{c}\text { Pre- } \\
\text { Test }\end{array}$ & Perlakuan & $\begin{array}{c}\text { Post- } \\
\text { test }\end{array}$ \\
\hline Eksperimen & 01 & $\mathrm{X}$ & 02 \\
\hline Kontrol & 01 & - & 02 \\
\hline
\end{tabular}

\section{Subjek Penelitian}

Subjek pada sampel ialah bagian dari populasi. Semua bagian dari populasi ialah sampel, terlepas dari apakah bagian itu mewakili karakteristik populasi secara lengkap ataupun tidak (Azwar, 2019). Populasi yang didapat berjumlah 53 orang. Adapun metode pengambilan sampel menggunakan metode Purposive Sampling yaitu tehnik penentuan sampel dengan pertimbangan tertentu (Sugiyono, 2018). Adapun karakteristik subjek penelitian antara lain yakni:

a. Anggota wanita Sriwijaya HypnoPranic Association Palembang angkatan 2017, 2018 dan 2019

b. Pendidikan terakhir SMA/Sederajat

c. Usia 16-24 tahun

d. Bersedia menjadi subjek penelitian

Berdasarkan karakteristik diatas, maka akan didapatkan subjek yang sesuai kriteria penelitian.

\section{Teknik Pengumpulan Data}

Teknik pengumpulan data dalam penelitian ini menggunakan tiga alat ukur yakni skala kepercayaan diri Lauster (Ghufron \& Risnawita, 2012), cheklist observasi dan kuesioner.

\section{Metode Analisis Data}

Metode analisis data adalah cara menganalisis data penelitian, termasuk alatalat statsitik yang relevan untuk digunakan dalam penelitian. Teknik analisis dalam penelitian ini menggunakan independent sample t-test. Independent Sample t-test merupakan uji hipotesis untuk melihat pengaruh dari variabel bebas terhadap variabel terikat. Kriteria pengujian independent sample t-test dengan uji T. Jika signifikansi <, maka Ho ditolak. Uji $\mathrm{T}$ bertujuan membandingkan nilai $\mathrm{t}$ hitung dengan $t$ tabel atau membandingkan nilai signifikansi. Jika $t$ hitung $<\mathrm{t}$ tabel maka Ho diterima, Jika $\mathrm{t}$ hitung $>\mathrm{t}$ tabel maka Ho ditolak. Jika signifikansi (2-tailed) $>\alpha$, maka Ho diterima, Jika signifikansi (2tailed) $<\alpha$, maka Ho ditolak (Alhamdu, 2016).

Penelitian ini menggunakan analisis uji statistik parametrik. Yang betujuan untuk melakukan uji perbandingan dan perbedaan rata-rata dari dua sampel baik data independen maupun data berpasangan dan data harus berdistribusi normal. Analisis tersebut menggunakan program SPSS (statistic program for social science) versi 22 dalam analisis datanya.

\section{Hasil dan Diskusi}

Adapun uji reliabilitas menggunakan analisis alpha cronbach, suatu alat ukur dikatakan reliabel jika memenuhi batas minimum skor Alpha cronbach 0,6. Artinya, skor reliabilitas alat ukur yang kurang dari 0.6 dianggap kurang baik, 
sedangkan skor 0.7 dianggap dapat diterima, dan dianggap baik bila mencapai skor 0,8 . Skor reliabilitas yang semakin mendekati 1, maka semakin baik dan tinggi skor reliabilitas alat ukur yang digunakan. Adapun hasil uji reliabilitas dapat dilihat dari tabel 2.

\section{Tabel 2.}

Reliabilitas

\begin{tabular}{ll}
\hline Skor & N \\
\hline 0,968 & 37 \\
\hline
\end{tabular}

Dari uji coba skala kepercayaan diri menunjukkan alpha cronbach sebesar 0.949 sebelum aitem gugur dikeluarkan, setelah aitem gugur dikeluarkan maka didapatkan alpha cronbach sebesar 0,968 karena alpha cronbach-nya telah mendekati 1 maka skala kepercayaan diri dapat dikatakan reliabel.

Dari uji coba skala kepercayaan diri menunjukkan alpha cronbach sebesar 0.949 sebelum aitem gugur dikeluarkan, setelah aitem gugur dikeluarkan maka didapatkan alpha cronbach sebesar 0,968 karena alpha

Hasil analisis dengan independent sample $t$ test menunjukkan bahwa hipnosis dapat meningkatkan kepercayaan diri pada anggota Sriwijaya Hypno-Pranic Association Palembang sehingga dapat dinyatakan hipotesis yang diajukan terbukti. Hal ini sesuai dengan pendapat Goldberg (2007) yang menyatakan bahwa salah satu manfaat proses kerja hipnosis yakni dapat meningkatkan rasa percaya diri pada individu.

Pada penelitian ini, peneliti menggunakan panduan berupa modul hipnosis yang dibuat sendiri oleh peneliti yang berisi latar belakang, dasar teori, tujuan, lokasi, alat dan bahan yang digunakan, metode, dan proses pelaksanaan. Pada proses pelaksanaan terdapat tiga tahap, yaitu tahap pertama (pelaksanaan joining) yang bertujuan untuk membangun hubungan yang akrab,memberikan informasi, perkenalan, melakukan kontrak kegiatan dan menunjukkan simpati kepada subjek. Kemudian tahap kedua (pelaksanaan pemberian hipnosis) yakni subjek diberikan perlakuan hipnosis oleh seorang terapis yang sudah ahli dalam bidangnya. Tahap pelaksanaan pemberian perlakuan hipnosis ini berlangsung selama 5 kali pertemuan. Dan terakhir tahap ketiga (terminasi) yang bertujuan untuk mengevaluasi dan mengukur perubahan subjek dan membuat kesan positif sebelum kegiatan diakhiri. Dalam melakukan perlakuan, peneliti dibantu dengan 9 observer dari mahasiswa UIN Raden Fatah Palembang semester VII angkatan 2017 Fakultas Psikologi untuk mengamati perilaku subjek saat penelitian berlangsung secara bergantian dengan menyesuaikan hari observer.

\section{Kesimpulan}

Berdasarkan hasil penelitian, dapat disimpulkan bahwa hipnosis memiliki pengaruh dalam meningkatkan kepercayaan diri anggota Sriwijaya HypnoPranic Association Palembang. Penelitian ini diperkuat dengan hasil analisis observasi perilaku yang menunjukkan bahwa ada pengaruh dalam pemberian perlakuan hipnosis pada meningkatkanya kepercayaan diri serta analisis statistik Independent Sample T-test yang menunjukkan bahwa hipnosis berpengaruh terhadap peningkatan kepercayaan diri anggota Sriwijaya Hypno-Pranic Association Palembang. 
Bagi anggota SHA Palembang yang khususnya masih belum percaya diri agar dapat melatih diri dengan selain menggunakan hipnosis juga menggunakan pelatihan di tempat atau kegiatan lainnya agar mendapatkan lebih banyak referensi dan pengalaman untuk menambah jam terbang dalam melatih kemampuan sehingga dapat melatih rasa percaya diri. Bagi anggota SHA Palembang yang khususnya masih belum percaya diri agar dapat melatih diri dengan selain menggunakan hipnosis juga menggunakan pelatihan di tempat atau kegiatan lainnya agar mendapatkan lebih banyak referensi dan pengalaman untuk menambah jam terbang dalam melatih kemampuan sehingga dapat melatih rasa percaya diri.

\section{Referensi}

Alhamdu. (2017). Kontruksi Tes. Palembang: Noer Fikri

Abraham H.M. (2018). Motivation and Personality (Terjemahan Achmad Fawaid \& Maufur). Yogyakarta: Cantrik Pustaka

Ajigen. (2019). Menjadi Percaya Diri Dihadapan Siapapun: Solusi Masalah Orang Pemalu, Cemas dan Pendiam. Demak: Ajigen

Alhamdu. (2016). Psikologi Eksperimen. Palembang: Noer Fikri

Aprillia, Y. (2010). Hipnostetri Rileks, Nyaman, dan Aman Saat Hamil \& Melahirkan. Jakarta: Gagasmedia

Azwar, S. (2019). Metode Penelitian Psikologi Edisi II. Yogyakarta: Pustaka Pelajar

Ghufron, M.N. \& Risnawita S, R. (2012). Teori-Teori Psikologi. Yogyakarta: Ar-Ruzz Media

Goldberg, B. (2007). SELF HYPNOSIS Bebas Masalah dengan Hypnosis. Yogyakarta: PT Bentang Pustaka
Gunawan, A. W. (2012). Hypnotherapy the art of subconscius restructuring. Jakarta: PT Gramedia Pustaka Utama

Gunawan, A.W. (2012). Hypnosis - The Art of Subconscius Communication Meraih Sukses dengan Kekuatan Pikiran. Jakarta: PT Gramedia Pustaka Utama

Hakim, A. (2010). Hypnosis in Teaching: Cara Dahsyat Mendidik \& Mengajar. Jakarta: Visimedia

Hakim, A. \& Wong, W. (2009). Dahsyatnya Hipnosis. Jakarta: Visimedia

Hosen, H.N. (2019). Tafsir Al-Quran di Medsos: Mengkaji Makna dan Rahasia Ayat Suci pada Era Media Sosial. Yogyakarta: Bentang Pustaka

Noor, J. (2017). Metode Penelitian: Skripsi, Tesis, Disertasi, dan Karya Ilmiah Edisi Pertama. Jakarta: Kencana

Putra, Y.P. (2013). Rahasia Dibalik Hipnosis Ericksonian Dan Metode Pengembangan Pikiran Lainnya. Jakarta: Elex Media Komputindo

Rafael. R. (2006). HIPNOTERAPI: Quit Smoking !. Jakarta: Gagasmedia

Subiyono, Surati, N., \& Hariono, A. (2015). Hypnometafisika: Solusi-Langkah-RadarKreativitas. Yogyakarta: Deepublish

Sugiyono. (2018). Metode Penenlitian Kuantitatif. Bandung: Alfabeda

Taylor, R. (2013). Kiat-Kiat Pede Untuk Meningkatkan Rasa Percaya Diri. Jakarta: Gramedia Pustaka Utama 